\title{
TRANSEXUALIDADE E EDUCAÇÃO EM DIREITOS HUMANOS: TRAJETÓRIAS E CONQUISTAS NO BRASIL
}

Flaviana de Freitas Oliveira ${ }^{1}$ Ana Maria Klein ${ }^{2}$

Resumo: A transexualidade é uma realidade existente em nossa sociedade contemporânea e que ainda sofre com alta carga de preconceito por parte dos setores mais conservadores. Caracterizase pela oposição entre identidade de gênero e sexo biológico. Estudos recentes demonstram que a determinação da identidade sexual decorre de critério morfológico, enquanto que o papel do gênero se apresenta como expressão pública dessa identidade. Para que sejam devidamente aceitas, as pessoas transexuais têm empenhado diversos movimentos sociais e ações educativas para que seus direitos sejam garantidos. Este artigo visa demonstrar que o direito à transexualidade é um direito humano e que a Educação em Direitos Humanos (EDH) contribui com a efetivação das conquistas transexuais no dia a dia. No Brasil, temos decisões judiciais e algumas leis esparsas para garantir os direitos desta população. Merece destaque o ano de 2018, em que o Supremo Tribunal Federal (STF) autorizou transexuais e travestis a mudarem prenome e sexo no Registro Civil sem necessidade de cirurgia de redesignação sexual e sem autorização judicial. Todas as conquistas estão baseadas na grande luta dos movimentos da população transexual e nas ações educativas de algumas organizações. Neste sentido, ressalta-se, no presente trabalho, a EDH como via de promover direitos e garantir dignidade aos transexuais.

\footnotetext{
${ }^{1}$ Mestranda em Ensino e Processos Formativos na Universidade Estadual Paulista (UNESP), campus de São José do Rio Preto. Graduada em Jornalismo pela UNESP e em Direito pelas Faculdades Integradas de Jaú (FIJ). É advogada inscrita na OAB/SP, subcoordenadora da Comissão de Direitos Humanos e secretária da Comissão de Diversidade Sexual e de Gênero da OAB de São José do Rio Preto

${ }^{2}$ Doutora e mestre em Educação pela Universidade de São Paulo (USP), graduada em Pedagogia e em Ciências Sociais (USP). É professora da graduação e da pós-graduação na Universidade Estadual Paulista (UNESP) de São José do Rio Preto.Participou da Comissão Relatora das Diretrizes Nacionais de EDH junto ao CNE, consultora ONU/UNESCO em EDH
} 
Palavras-chave: $\quad$ Transexualidade.

Direitos Transexuais. Direitos Humanos. Educação em Direitos Humanos.

Resumen: La transexualidad es una realidad existente en nuestra sociedad contemporánea y que todavía sufre con alta carga de prejuicio por parte de los sectores más conservadores. Se caracteriza por la oposición entre identidad de género y sexo biológico. Estudios recientes demuestran que la determinación de la identidad sexual deriva de un criterio morfológico, mientras que el papel del género se presenta como expresión pública de esa identidad. Para que sean debidamente aceptadas, las personas transexuales han empeñado diversos movimientos sociales y acciones educativas para que sus derechos sean garantizados. Este artículo pretende demostrar que el derecho a la transexualidad es un derecho humano y que la Educación en Derechos Humanos (EDH) contribuye con la efectividad de las conquistas transexuales en el día a día. En Brasil, tenemos decisiones judiciales y algunas leyes escasas para garantizar los derechos de esta población. Se destaca el año 2018, en el que el Supremo Tribunal Federal (STF) autorizó a transexuales y travestis a cambiar el nombre y el sexo en el Registro Civil sin necesidad de cirugía de reasignación sexual y sin autorización judicial. Todas las conquistas se basan en la gran lucha de los movimientos de la población transexual y en las acciones educativas de algunas organizaciones. En este sentido, se resalta, en el presente trabajo, la EDH como vía de promover derechos y garantizar dignidad a los transexuales.

Palabras clave: Transexualidad. Derechos transexuales. Derechos humanos. Educación en Derechos Humanos.

\section{Introdução}

Vivemos em uma sociedade contemporânea e democrática, em que convivem diversos grupos heterogêneos, caracterizando-se pela multiplicidade e pluralidade social. Assim, a suposta "normalidade", representada pela heteronormatividade (que se baseia no padrão de homem, heterossexual e branco), é muitas vezes colocada em cheque por setores sociais que não se enquadram no padrão imposto.

A transexualidade, caracterizada pela discrepância entre identidade de 
gênero e sexo biológico, tem resistência de aceitação por grande parte da sociedade. Ao longo do tempo, homens e mulheres conseguiram maior liberdade e autonomia para exercer sua sexualidade, mas este direito ainda é restrito aos homossexuais e transexuais.

É neste contexto que os transexuais, até então socialmente escondidos e, por conseguinte, excluídos, necessitam encontrar o seu espaço social. Para que ocorra a devida aceitação social da transexualidade no cenário contemporâneo, a Educação em Direitos Humanos (EDH) aparece como importante ferramenta. Educar em e para os direitos humanos é fazer com que o indivíduo reconheça o outro como igual, como ser humano, com todas as diferenças e diversidades inerentes a cada pessoa.

A população transexual almeja o reconhecimento a uma vida digna, com a livre expressão de sua identidade de gênero e de sua sexualidade. Apesar do forte preconceito existente no Brasil e de vivermos em tempos de retrocesso de Direitos Humanos, algumas conquistas têm sido efetivadas para a população transexual. A sociedade não é estática e o Estado não pode permanecer inalterável às mudanças sociais, que fazem parte da evolução de nossa civilização.

O objetivo deste artigo é apresentar a transexualidade como direito humano e analisar como a EDH, por meio da educação formal ou dos movimentos sociais (não-formal), pode contribuir para efetivar este direito. Além disso, visa-se analisar quais são as conquistas da população transexual no Brasil, tanto no Legislativo quanto no Judiciário. O intuito é construir uma relação inexorável entre os direitos humanos, o direito à transexualidade e o papel da educação.

Assim, a EDH, que pode ocorrer do ponto de vista formal, não-formal ou informal, é uma importante via para que possamos atingir uma sociedade mais justa e sem preconceito. Neste contexto, ressalta-se a prática educativa como forma de garantir o direito à transexualidade e sua aceitação social.

\section{Definição de transexualidade}

Diversos estudos, nos dias de hoje, revelam que o conceito de mulher e de feminilidade foi construído socialmente e, portanto, nada tem a ver com o sexo biológico. De acordo com a Coordenação de Políticas para a 
Diversidade Sexual do Estado de São Paulo (2017), o conceito de gênero, formulado nos anos 1970, foi criado para distinguir a dimensão biológica da dimensão social. Embora a biologia divida a espécie humana entre machos e fêmeas, a maneira de ser homem e ser mulher é expressa pela cultura. Assim, homens e mulheres são produtos da realidade social, e não decorrência direta da anatomia de seus corpos.

A identidade de gênero é a percepção íntima que uma pessoa tem de si como sendo do gênero masculino, feminino ou de alguma combinação de ambos, independente do sexo biológico. Estes comportamentos são construídos culturalmente, variam de acordo com a sociedade e não são naturais, ou seja, não nascem com a pessoa. (Coordenação de Políticas para a Diversidade Sexual, 2017: 17-18)

Butler (2003) diz que, a partir do momento em que o gênero é construído socialmente, ele pode ser diferente da construção predominante. Ela ressalta, entretanto, que o determinismo social, de alguma forma, exclui a possibilidade de transformação. Embora haja distinção entre sexo biológico e identidade de gênero, $\mathrm{o}$ comportamento social fortemente baseado na heteronormatividade faz com que a sociedade seja um espaço obstinado na produção, reprodução e atualização desses parâmetros.

Para a autora, a ideia de gênero construído sugere um determinismo de significados de gênero, "inscritos em corpos compreendidos como recipientes passivos de uma lei cultural inexorável". Dessa forma, quando o gênero é visto nesses termos, passa a ser tão fixo quanto na formulação biológica. "Nesse caso, não a biologia, mas a cultura se torna o destino" (Butler, 2003: 26).

Com o entendimento de que identidade de gênero nada tem a ver com sexo biológico, fica mais simples entender o conceito de transexualidade.

A pessoa transexual é aquela cuja identidade de gênero é contrária ao seu sexo biológico.

Transexual é o indivíduo que possui a convicção inalterável de pertencer ao sexo oposto ao constante em seu Registro de Nascimento, reprovando veementemente seus órgãos sexuais externos, dos quais deseja se livrar por meio de cirurgia. Segundo uma concepção moderna o transexual masculino é uma mulher com corpo de homem. Um transexual feminino é, evidentemente, o contrário. São, portanto, portadores de neurodiscordância de gênero. Suas reações são, em geral, aquelas próprias do sexo com o qual se identifica psíquica e socialmente. Culpar este indivíduo é o mesmo que culpar a bússola por apontar para o norte. (Vieira, 2004: 47) 
Dias (2016) afirma que a determinação da identidade sexual decorre de critério morfológico, enquanto que o papel do gênero se apresenta como expressão pública dessa identidade. Assim, a transexualidade se caracteriza quando uma pessoa se considera pertencente ao sexo oposto, sentindo "desconexão psíquicoemocional com o seu sexo biológico" (Dias, 2016: 227).

A transexualidade causa tanta estranheza ao setor conservador da sociedade porque desafia a chamada heteronormatividade, padrão de sexualidade que regula o modo como as sociedades estão organizadas. Nas palavras de Luzzardi e Cardoso (2017), tanto a sociedade capitalista ocidental como a oriental baseiam-se numa matriz patriarcal e heteronormativa, uma organização social fundada no poder masculino e na qual predomina a heterossexualidade.

Para Petry e Meyer (2011: 196), trata-se de "um significado que exerce o poder de ratificar, na cultura, a compreensão de que a norma e o normal são as relações existentes entre pessoas de sexos diferentes", além da identidade de gênero coerente com o sexo biológico. Bento (2017) diz que essa ruptura com o socialmente imposto traz inúmeras angústias para o indivíduo transexual.

Afirmar que a transexualidade é uma experiência identitária, que está relacionada à capacidade dos sujeitos construírem novos sentidos para os masculinos e os femininos, não significa esquecer a dor e a angústia que marcam as subjetividades daqueles que sentem e desejam viver experiências que lhes são interditas por não terem comportamentos considerados apropriados para seus sexos. As narrativas das pessoas transexuais nos remetem para um mundo de dúvidas, angústias, solidão e um medo constante de serem rejeitados. Nos relatos biográficos nota-se que sentem dificuldades em falar de seus conflitos porque não sabem como nomeá-los. Como explicar que seu desejo é usar as cores, as roupas, os acessórios e reconstruir o corpo com signos pertencentes ao outro gênero? Como encontrar sentido para este desejo se o corpo carrega um genital que atua como o obstaculizador desse trânsito? (Bento, 2017: 22-23)

A partir deste entendimento, estabelece-se que a transexualidade quebra a causalidade entre sexo, gênero e desejo e rompe com os limites de um sistema binário, que associa o pênis à masculinidade e a vagina à feminilidade. Conforme exposto, a identidade de gênero não se trata de algo biológico ou natural, mas de uma construção social. Assim, cada pessoa tem direito a ser 
tratada de acordo com a identidade de gênero com a qual se identifica.

Um exemplo é a questão do nome, visto que pessoas transexuais não se identificam com o nome que lhes é dado no nascimento (masculino ou feminino). Dias (2016) ressalta que identidade de gênero é uma experiência interna de cada indivíduo, que pode ou não corresponder ao sexo e ao nome atribuído no nascimento.

O nome registral do cidadão trans não remete à sua identidade, mas justamente a afronta. A despeito de sua expressão de gênero, de sua vestimenta, a despeito das intervenções cirúrgica, a falta de um nome correspondente ao gênero sujeita transexuais $\mathrm{e}$ travestis a ter sua identidade constantemente revelada e violada, a ser humilhado e tratado pelo sexo que não o identifica. (Dias, 2016: 227)

Considerando o gênero como uma construção social e cultural, e que não está necessariamente vinculado à anatomia, entendemos o significado da transexualidade, que nada mais seria que se identificar no gênero oposto ao do sexo biológico. A liberdade de ser transexual e exercer sua sexualidade é um direito humano, diretamente ligado com os direitos de personalidade, sexualidade, intimidade e liberdade.
Para que este direito possa ser exercido e aceito socialmente, as pessoas precisam ser educadas em e para os Direitos Humanos, de forma a entendêlos e valorá-los no cotidiano, diminuindo assim toda a carga de preconceito que pessoas transexuais sofrem todos os dias, principalmente no Brasil.

\section{A transexualidade como direito}

\section{humano}

Os Direitos Humanos foram construídos historicamente e tem como marco contemporâneo a elaboração da Declaração Universal dos Direitos Humanos (ONU, 1948). Nas últimas décadas, eles foram sendo positivados por todo o mundo, nas mais variadas formas de manifestação. Mesmo com o cenário de avanço dos Direitos Humanos, a situação dos transexuais ainda é marginalizada, visto que há resistência de aceitação da sociedade, que ocorre principalmente por causa do preconceito.

Scheibe (2008) expõe que resgatar essa minoria social em um Estado Democrático de Direito, espaço preservador da convivência humana que aponta a dignidade concreta como núcleo fundamental, é imprescindível e 
impositivo, tendo em vista ser nítido o sofrimento psíquico do transexual por conviver com a frustração de pertencer ao sexo não desejado.

Segundo Arendt (2013), a solidão, a experiência de não pertencer ao mundo, "é uma das mais radicais e desesperadoras experiências que o ser humano pode ter". Portanto, não aceitar a identidade de gênero de um ser humano, é fazer com que o indivíduo perca o senso de pertencimento à sociedade, o que seria uma triste violação dos Direitos Humanos desta pessoa.

Kant (1986), ao escrever sobre a dignidade humana e a moral, explica a importância de determinados direitos:

No reino dos fins tudo tem um preço ou uma dignidade. Quando uma coisa tem um preço, pode-se pôr em vez dela qualquer outra como equivalente, mas quando uma coisa está acima de todo o preço e, portanto, não permite equivalente, então tem ela dignidade. $\mathrm{O}$ direito à vida, à honra, à integridade física, à integridade psíquica, à privacidade, dentre outros, são essencialmente tais, pois, sem eles, não se concretiza a dignidade humana. A cada pessoa não é conferido o poder de dispô-los, sob pena de reduzir sua condição humana, todas as demais pessoas devem abster-se de violá-los. (Kant, 1986: 77)

A partir da percepção de Kant (1986) sobre a dignidade humana, observa-se o quanto a transexualidade está relacionada aos Direitos Humanos. Os transexuais têm sua sexualidade tutelada por princípios presentes na Declaração Universal dos Direitos Humanos (ONU, 1948) e na nossa Constituição Federal (BRASIL, 1988), pois gozam dos direitos à personalidade, à identidade, à dignidade, à igualdade, à cidadania e à privacidade.

Os Direitos Humanos, do ponto de vista teórico e didático, são divididos em quatro gerações. A primeira inclui os direitos civis e políticos, relacionados ao princípio da liberdade e que possuem aplicação imediata. A segunda geração inclui os direitos econômicos, sociais e culturais, que possuem aplicação progressiva e se relacionam com o princípio da igualdade. A terceira geração inclui os direitos a uma nova internacional, como o direito à paz e ao desenvolvimento, ligados à fraternidade social. Por fim, tem-se a quarta geração, uma categoria nova de direitos e que se refere às gerações futuras (Tosi, 2005).

Bobbio (1996) entende a redesignação sexual como direito humano de quarta geração, por estar inserida no campo da Bioética, abrangendo "um conjunto de direitos diretamente resultantes dos novos 
conhecimentos e tecnologias decorrentes das pesquisas científicas" (Bobbio, 1996: 5). Para o autor, a mudança - ou não - de sexo do transexual é um direito humano que tem abrangência multidisciplinar de ramos como a Medicina, a Psicologia, a Biologia, a Sociologia, a Filosofia e o Direito.

Dessa forma, percebe-se que os princípios relacionados aos Direitos Humanos estão amplamente vinculados ao direito à transexualidade. A própria questão da redesignação sexual, tão presente no debate da transexualidade, poderia ser considerada um direito humano de quarta geração. A diversidade é, sem dúvida, uma das principais características quando pensamos na humanidade. Os seres humanos são plurais e, por isso, suas diferenças devem ser entendidas e aceitas, corriqueiramente.

Para isso, os Direitos Humanos devem ser pensados como elementos democráticos, construídos a partir dos movimentos sociais, para que haja cada vez mais respeito às diversidades.

Só podemos entender os direitos humanos alicerçados numa nova forma de democracia, não evolucionista, que congregue participação ampla de distintas comunidades políticas, com formas legítimas de governo com sólido compromisso com os direitos e os deveres, que emirjam das necessidades e aspirações de suas populações, ou seja, verdadeiramente democráticos. Não queremos, com isso, almejar uma sociedade de cidadãos culturalmente idênticos, mas diversos e plurais, com manifestações próprias, mas que tenham respeito às diversidades de seus congêneres humanos. (RIBEIRO, 2012: 140)

Pensar no respeito à diferença $\mathrm{e}$ na igualdade de direitos é fundamental na aceitação da transexualidade. É entender a diversidade sexual, em todas as suas variações, e reconhecer na pessoa transexual um igual, titular dos mesmos direitos e deveres. Portanto, o direito ao equilíbrio da mente e do corpo da pessoa transexual trata-se de um direito humano e de personalidade do indivíduo (Viegas et al., 2013).

Ao se levar em conta a legislação internacional de Direitos Humanos, percebe-se que há um rol de direitos a serem aplicados pelos estados signatários. A Convenção Americana de Direitos Humanos - Pacto de San Jose da Costa Rica (OEA, 1969), da qual o Brasil é signatário, impõe o respeito ao direito ao nome (artigo 18), ao reconhecimento da personalidade jurídica (artigo $3^{\circ}$ ), à liberdade pessoal (artigo $7^{\circ} .1$ ) e à honra e à dignidade (artigo 11.2). Todos esses 
dispositivos devem ser observados, sob pena de responsabilidade internacional.

A Opinião Consultiva n ${ }^{\circ} 24 / 17$ da Corte Interamericana de Direitos Humanos (2017), que trata da identidade de gênero, igualdade e não discriminação, define as obrigações dos Estados-Parte no que se refere à alteração do nome e à identidade de gênero.

Não pode o Estado Brasileiro, sabendo que o direito à transexualidade se enquadra em diversos princípios e dispositivos da Constituição Federal e da legislação internacional da qual o país é signatário, deixar de intervir para garantir direitos à população transexual, seja por omissão legislativa ou por falta de políticas públicas efetivas. Com a pressão dos movimentos sociais mais evidentes nos últimos anos, o Brasil tem dado passos no sentido de efetivar os Direitos Humanos das pessoas transexuais.

\section{EDH, movimentos sociais e formação de sujeitos}

Desde a elaboração da Declaração Universal dos Direitos Humanos (ONU, 1948), há o reconhecimento da imprescindibilidade da educação como via para enfrentar e prevenir as violações de direitos. O Preâmbulo do documento ressalta o papel da Educação em Direitos Humanos $(\mathrm{EDH})$.

[..] o ideal comum a ser atingido por todos os povos e todas as nações, com o objetivo de que cada indivíduo e cada órgão da sociedade, tendo sempre em mente esta Declaração, se esforce, através do ensino e da educação, por promover o respeito a esses direitos e liberdades, e, pela adoção de medidas progressivas de caráter nacional e internacional, por assegurar o seu reconhecimento e a sua observância universal e efetiva (ONU, 1948: Preâmbulo).

No Brasil, o debate sobre a EDH ganhou força no fim da década de 1980, quando houve o processo de redemocratização do país e a promulgação da Constituição Federal de 1988, considerada a Constituição Cidadã, por ter incorporado diversos valores relacionados aos Direitos Humanos.

A Década da Organização das Nações Unidas (ONU) para a EDH teve início em janeiro de 1995 e, em julho de 2003, o Brasil tornou oficial a Educação em Direitos Humanos como política pública. Em dezembro de 2003, foi lançada a primeira versão do Plano Nacional de Educação em Direitos 
Humanos - PNEDH (Brasil, 2007), considerado instrumento orientador e fomentador de ações educativas nas seguintes áreas: educação básica; ensino superior; educação não-formal; educação dos profissionais dos sistemas de justiça e segurança; e educação e mídia.

De acordo com o PNEDH (Brasil, 2007), “a Educação em Direitos Humanos é compreendida como um processo sistemático e multidimensional que orienta a formação do sujeito de direitos". Trata-se da articulação das seguintes dimensões:

a) apreensão de conhecimentos historicamente construídos sobre direitos humanos e a sua relação com os contextos internacional, nacional e local;

b) afirmação de valores, atitudes e práticas sociais que expressem a cultura dos direitos humanos em todos os espaços da sociedade;

c) formação de uma consciência cidadã capaz de se fazer presente em níveis cognitivo, social, ético e político;

d) desenvolvimento de processos metodológicos participativos e de construção coletiva, utilizando linguagens e materiais didáticos contextualizados;

e) fortalecimento de práticas individuais e sociais que gerem ações e instrumentos em favor da promoção, da proteção e da defesa dos direitos humanos, bem como da reparação das violações. (Brasil, 2007: 17)

Vale ressaltar que o documento foi pensado para contribuir com a construção de uma cultura voltada para o respeito aos direitos fundamentais da pessoa humana, envolvendo diferentes segmentos sociais, órgãos públicos $\mathrm{e}$ privados e esferas do governo (Brasil, 2013). Além disso, o documento incluiu em seus eixos tanto a educação formal, como a não-formal e a informal.

Neste ponto, é necessário um parêntese para explicitar o que significa a educação não-formal do ponto de vista do PNEDH (Brasil, 2007). A Educação em Direitos Humanos não-formal é realizada fora das escolas, orientando-se pelos princípios da emancipação e da autonomia. Assim dispõe o PNEDH:

Os espaços das atividades de educação não-formal distribuemse em inúmeras dimensões, incluindo desde as ações das comunidades, dos movimentos e organizações sociais, políticas e não-governamentais até as do setor da educação e da cultura. Essas atividades se desenvolvem em duas vertentes principais: a construção do conhecimento em educação popular e o processo de participação em ações coletivas, tendo a cidadania democrática como foco central. Nesse sentido, movimentos sociais, entidades civis e partidos políticos praticam educação não-formal quando estimulam os grupos sociais a refletirem sobre as suas próprias condições de vida, os processos históricos em que estão inseridos e o papel que desempenham na sociedade contemporânea. (p. 43) 
Assim, conforme disposto no PNEDH (BrasilL, 2007), os movimentos sociais se caracterizam como processo de educação não-formal, visto que educam a população, ainda que educar não seja seu principal objetivo. Gohn (2009) explica como os movimentos estão encaixados neste tipo de educação:

São processos de
autoaprendizagem e aprendizagem
coletiva adquirida a partir da
experiência em ações organizadas
segundo os eixos temáticos:
questões étnico-raciais, gênero,
geracionais e de idade, etc. As
práticas da educação não-formal se
desenvolvem usualmente
extramuros escolares, nas
organizações sociais, nos
movimentos, nos programas de
formação sobre direitos humanos,
cidadania, práticas identitárias,
lutas contra desigualdades e
exclusões sociais. (Gohn, 2009:
31)

O Parecer CNE/CP n ${ }^{\circ} 8 / 2012$

(Brasil, 2012), que institui as Diretrizes Nacionais para a Educação em Direitos Humanos, ressalta que a EDH se fundamenta também nos princípios da dignidade humana; igualdade de direitos; reconhecimento e valorização das diferenças e das diversidades; laicidade do Estado; democracia na educação; transversalidade, vivência e globalidade; e sustentabilidade socioambiental. Assim, estes princípios tornam-se inerentes ao processo de
Educação em Direitos Humanos. O Parecer CNE/CP n 8/2012 (Brasil, 2012) ainda ressalta como os processos formativos e educativos envolvem diversos contextos de socialização, como a comunidade, a família, os meios de comunicação, as instituições escolares, dentre outros.

Dessa forma, percebe-se a importância que o Estado atribui à Educação em Direitos Humanos, além de sua amplitude e complexidade para ser plenamente aplicada nos mais diversos segmentos. Os documentos que tratam da EDH no Brasil ressaltam a importância de que os trabalhos educativos estejam em todas as instâncias e apontam, também, a importância de se garantir a igualdade e a valorização das diversidades.

Do ponto de vista da transexualidade, o debate sobre o tema ganhou mais destaque no cotidiano social nos últimos anos, principalmente na mídia (que é educadora informal). Dinis (2008), entretanto, opina que o maior reconhecimento da diversidade sexual não implica necessariamente em maior aceitação social:

Se a visibilidade de formas alternativas de viver a sexualidade, tematizadas pela mídia, impõe 
certo reconhecimento das causas ligadas às minorias sexuais e de gênero, forçando também a escola a rever padrões normativos que produzem a sexualidade das/dos estudantes, por outro lado também não deixa de acirrar manifestações de grupos mais conservadores. Pois, em um momento histórico em que mais se fala sobre educar para a diferença, vivemos um cenário político mundial de intolerância que se repete também no espaço da vida privada, em determinada dificuldade generalizada em nos libertarmos de formas padronizadas de concebermos nossa relação com o outro. (Dinis, 2008: 479)

O cenário de intolerância, cominado com as baixas políticas públicas e leis relacionadas à transexualidade, fazem com que a educação seja relevante para formar uma sociedade educada para a diversidade e a tolerância. Com este intuito, é necessário abrir mão de concepções essencialistas em prol de uma Educação em Direitos Humanos, especialmente quando se trata da diversidade sexual e de gênero.

Os Direitos Humanos integram nosso cotidiano e estão presentes nas relações de todos os seres humanos. Para que haja esta percepção, no entanto, são necessários os processos educativos, sejam eles formais, não-formais ou informais. Por meio da educação, as pessoas podem conhecer seus direitos, reconhecê-los no cotidiano e posicionar- se criticamente sobre a sua aplicação no dia a dia, o que é fundamental para que os Direitos Humanos sejam devidamente efetivados.

\section{Direitos transexuais efetivados no Brasil}

A sociedade brasileira, ao longo da história, estruturou-se a partir de pressupostos sociais baseados na suposta "normalidade". Assim, formou-se um conjunto dinâmico de valores, normas e crenças responsável por reduzir a figura daqueles que não se encaixassem no padrão referencial do ser humano masculino, branco, heterossexual, burguês e sem deficiências físicas e psíquicas.

A chamada heteronormatividade faz com que tenhamos em nosso país um cenário de preconceito e violações de direitos. Dados do Mapa dos Assassinatos de Travestis e Transexuais, da Associação Nacional de Travestis e Transexuais (ANTRA, 2017), mostram que a taxa de homicídio de pessoas trans em 2017 foi a maior registrada nos últimos dez anos no Brasil. Foram 179 assassinatos de transexuais e travestis, um aumento de 15\% em relação a 2016. 
As estatísticas levam o Brasil a ocupar o primeiro lugar em assassinatos de travestis e transexuais do mundo. Atrás do Brasil, está o México, com 56 mortes, menos de um terço da quantidade registrada no Brasil. A comparação foi feita com base nos dados da ONG Internacional Transgender Europe (TGEU).

Em $94 \%$ dos casos, as vítimas eram mulheres, no qual, $67,9 \%$ das vítimas eram extremamente jovens, com idade entre 16 e 29 anos. Ao pensarmos na juventude, deparamo-nos com a questão escolar, que também tem dados desanimadores. A Pesquisa Nacional sobre Estudantes LGBT e o Ambiente Escolar, realizada em 2015 (ABGLT, 2016), revela que, no Brasil, 72,6\% dos estudantes LGBT já foram verbalmente agredidos por causa da orientação sexual. A porcentagem observada é a mais alta entre os países participantes do estudo (Brasil, Argentina, Peru, Colômbia, Chile e Uruguai).

Embora estejamos em tempos de retrocesso, em que os Direitos Humanos têm sido amplamente questionados e considerados como direitos de poucos e que não possuem relevância, algumas decisões judiciais e legislações esparsas têm garantido, aos poucos, os direitos transexuais.

O Brasil tem tido alguns avanços quando se trata da transexualidade. $\mathrm{O}$ principalmente acontecimento, que foi considerado uma grande vitória pelo movimento das pessoas transexuais, foi uma autorização dada pelo Supremo Tribunal Federal (STF), em março de 2018, para que transexuais e travestis possam alterar seu prenome e gênero no registro civil sem cirurgia de mudança de sexo e sem necessidade de autorização judicial.

Até esta decisão do STF, para que um transexual pudesse mudar seu nome e gênero, era necessário passar por todo um processo judicial, em que só poderia haver a mudança se houvesse autorização do juiz. Além disso, a regra era de que houvesse a cirurgia de redesignação sexual para que ocorresse a alteração.

Entende-se que o transexual tem o direito de se autodeterminar e independentemente de realizar a cirurgia de redesignação de sexo pode ter o seu nome e sexo alterados, fundamentado no princípio da dignidade humana que impõe a proteção do ser humano concretamente considerado. Com a personalização dos institutos jurídicos, o princípio passou não somente a representar um limite à atuação do Estado, mas também um caminho para a sua atuação 
positiva, garantindo o mínimo existencial e dando ao ser humano o direito de ser feliz. (Viegas et al., 2013: s/p)

Dessa forma, a decisão do STF foi relevante para consolidar o posicionamento de que o direito de personalidade diz respeito aos transexuais e todas suas decisões. A decisão ocorreu por conta de julgamento de Ação Direta de Inconstitucionalidade (ADI) $\mathrm{n}^{\mathrm{o}} 4275$, proposta pela Procuradoria Geral da República (Brasil, 2018), que pediu o reconhecimento de transexuais, que assim desejarem, a substituição do prenome e do sexo no registro civil, independente da cirurgia de transgenitalização.

Outra decisão recente importante, que ocorreu em escala mundial, foi da Organização Mundial da Saúde (OMS, 2018), que retirou a transexualidade da categoria de "distúrbios mentais" na Classificação Internacional de Doenças (CID-11). A atualização é um marco e acontece mais de 40 anos depois de a homossexualidade também ser retirada da lista, na década de 1990.

Apesar do avanço ao retirar dos “distúrbios mentais", a transexualidade foi mantida na CID e movida para a
30

categoria de "condição relativa à saúde sexual". Ao manter a transexualidade na lista, a OMS foi criticada por diversos movimentos sociais, mas afirmou que a medida ainda era necessária para garantir cuidados de saúde.

No Brasil, a cirurgia de redesignação sexual é permitida e pode ser feita pelo Sistema Único de Saúde (SUS). Para tanto, os interessados devem possuir alguns requisitos: maioridade, acompanhamento psicoterápico por pelo menos dois anos, laudo psicológico/psiquiátrico favorável e diagnóstico de transexualidade. O último requisito tem relação direta com a decisão de manter a transexualidade na CID, visto que para a mudança de sexo a pessoa interessada deve ter um "diagnóstico de doença".

Ao desconsiderar a transexualidade como "doença mental", a decisão da OMS reforça estigmas, pois continua a institucionalizar a transexualidade como doença, presente na CID. Em nosso país, apenas quatro hospitais fazem a cirurgia de transgenitalização e o processo pode demorar até 20 anos. Dias (2016) reforça que, mesmo sendo possível a realização do procedimento de readequação de identidade de gênero pelo SUS, são 
"poucos os complexos hospitalares que dispõem deste serviço, e longos são os prazos para ingressar no programar e realizar a cirurgia".

Em relação ao nome social, muitos órgãos brasileiros já admitem o uso, como os órgãos, fundações e autarquias da administração federal, a Ordem dos Advogados do Brasil, o Conselho Federal de Psicologia, entre outros. Também em 2018, em janeiro, o Ministério da Educação (MEC) homologou a Resolução CNE/CP $\mathrm{n}^{\circ}$ 1/2018, que autoriza o uso do nome social de travestis e transexuais nos registros escolares da educação básica.

Tal entendimento já era praticado no Estado de São Paulo, que possui a Resolução SE $n^{\circ} \quad 45 / 2014$ (SÃO PAULO, 2014), que também dispõe sobre o tratamento nominal de estudantes transexuais e travestis. $\mathrm{O}$ Estado de São Paulo, ainda possui a Lei 10.948/01 (São Paulo, 2001), que prevê que toda manifestação atentatória ou discriminatória praticada contra cidadão homossexual, bissexual ou transgênero será punida. Assim, praticar qualquer tipo de ação violenta, constrangedora, intimidatória ou vexatória, de ordem moral, ética, filosófica ou psicológica, ou proibir a livre expressão e manifestação de afetividade são atitudes retaliadas pela lei estadual.

Em âmbito nacional, não há uma lei que criminalize a transfobia. Aliás, são esparsas as legislações relacionadas aos direitos transexuais, sendo que muitos direitos são garantidos por meio de julgamentos do Judiciário. Apesar das incertezas e injustiças decorrentes da ausência de normas legais, o Estatuto da Diversidade Sexual, Projeto de Lei do Senado $n^{\circ}$ 134/2018 (Brasil, 2018), elaborado pela Comissão da Diversidade Sexual da $\mathrm{OAB}$, não foi aprovado ainda no Congresso Nacional. São vários os direitos garantidos às pessoas transexuais por meio do estatuto (Dias, 2016).

$\mathrm{O}$ projeto se aprovado, passa a assegurar, com força de lei, o direito à livre orientação sexual; à igualdade e a não discriminação; à convivência familiar, à identidade de gênero; à saúde; à educação; ao trabalho; à moradia; à justiça e à segurança; além de direitos previdenciários. Além disso, criminaliza a transfobia e a homofobia, além de propor diversas políticas públicas.

Dessa forma, percebe-se que muitos são os avanços recentes, principalmente em 2018. Porém, ainda há um longo caminho a trilharmos para 
garantir que os direitos transexuais sejam reconhecidos em sua plenitude, proporcionando às pessoas o direito à transexualidade e à livre identidade de gênero. O processo, embora longo, tem dado passos por causa das ações sociais e educativas propostas por diversos setores da sociedade. A Educação em Direitos Humanos tem sido basilar para o reconhecimento da transexualidade no Brasil.

\section{A contribuição da EDH para efetivação dos direitos transexuais}

Os direitos transexuais efetivados no Brasil, sejam por meio de legislação ou por meio de decisões judiciárias, são frutos de um longo processo de movimentação e resistência, no qual está inserido a Educação em Direitos Humanos. Sabe-se a importância da educação para que a sociedade possa entender determinado direito e passar a valorá-lo em seu cotidiano, portanto a $\mathrm{EDH}$ teve papel fundamental na efetivação dos direitos transexuais.

O movimento pelos direitos de lésbicas, gays, bissexuais, travestis e transexuais (LGBT) no Brasil começou a partir de reuniões em espaços sociais, como bares e clubes nos anos 1970, em plena ditadura (1964-1985). O protagonismo ficou por conta de organizações não governamentais e integrantes do movimento LGBT, que ao longo dos anos fizeram diversas ações, educativas ou não (educação não-formal e informal), para pressionar o Estado na adoção de políticas públicas.

A partir deste contexto, o Ministério da Educação (MEC) lançou diversos editais para contribuir com a aceitação da diversidade sexual em ambiente escolar e houve o lançamento do Programa Brasil Sem Homofobia (Brasil, 2004), a partir de uma série de discussões entre o Governo Federal e a sociedade civil organizada.

O Programa foi um marco na efetivação dos direitos transexuais, visto que foi lançado antes da maioria das decisões judiciais e da legislação em prol da transexualidade. Entre as ações do Programa Brasil Sem Homofobia, estão o apoio a projetos de fortalecimento de instituições que atuam na promoção da cidadania LGBT; a capacitação em direitos humanos para profissionais e representantes do movimento LGBT; e a disseminação de informações sobre direitos e incentivo à denúncia de violações dos Direitos Humanos da população LGBT. 
A movimentação em prol dos direitos LGBT foi definitiva para consolidar o diálogo entre o Estado e a população transexual, lembrando que os movimentos sociais fazem parte da Educação em Direitos Humanos nãoformal. Assim, o movimento LGBT, que ganhou força desde a ditadura militar, levou o Estado a organizar mais políticas públicas.

No caso das demandas do movimento LGBT no âmbito das políticas públicas de educação, cabe enfatizar que elas foram precedidas por um longo processo de consolidação do movimento, cujas interlocuções foram inicialmente voltadas para a área da saúde, do combate à AIDS, que, aos poucos, somaram-se ao combate à homofobia e às agendas feministas. (Vianna, 2015: 797)

A dinâmica ocorrida no Brasil entre Educação em Direitos Humanos e políticas públicas de educação para a diversidade sexual envolveu movimentos internacionais e nacionais, especialistas de diversos setores e a mídia. A partir desse contexto, o Judiciário passou a enxergar mais claramente as reinvindicações do movimento LGBT e novos projetos de lei em prol desta parcela da sociedade começaram a existir.

Dessa forma, considerando-se que a Educação em Direitos Humanos abrange também a educação não-formal e informal, podemos dizer que teve papel relevante para que $\mathrm{o}$ direito à transexualidade entrasse na pauta de políticas públicas e de direitos a serem consagrados no Brasil, principalmente por meio dos movimentos sociais. Não se conquista novos direitos sem movimentação, resistência e educação. É a partir da educação em e para os direitos humanos que se torna possível construir uma sociedade mais justa e igualitária.

\section{Considerações finais}

A realidade da pessoa transexual, como demonstrado, é permeada de dificuldades relativas à vida em sociedade e aos seus direitos. Para consolidar os Direitos Humanos e cumprir com a dignidade da pessoa humana, o Brasil precisa estar atento às mudanças sociais e aos novos valores incorporados na forma de viver de seus cidadãos.

Este artigo buscou mostrar o que significa a transexualidade e porque $o$ direito à transexualidade é um direito humano, revelando o papel da Educação em Direitos Humanos para efetivação das conquistas sociais. Omitir-se perante o preconceito de parte da sociedade 
significa deixar diversas pessoas silenciadas na reinvindicação de seus direitos.

A identidade de gênero é uma convicção íntima da pessoa em pertencer ao gênero masculino ou feminino, que pode ou não corresponder ao sexo atribuído no nascimento (Dias, 2016). Diariamente, transexuais são alvo de violência, sendo que o Brasil é o país que mais mata travestis e transexuais no mundo.

Neste contexto, estar atento às evoluções sociais e aplicar a Educação em Direitos Humanos no dia a dia das pessoas é fundamental para que possamos construir maior igualdade de direitos. Garantir às pessoas transexuais seus direitos fundamentais, é estar coadunado com a legislação internacional de Direitos Humanos e com a nossa Constituição Federal, amplamente baseada na dignidade da pessoa humana.

\section{Referências Bibliográficas}

Arendt, Hannah (2013), Origens do totalitarismo. São Paulo: Companhia das Letras.

Associação Brasileira de Lésbicas, Gays, Bissexuais, Travestis e Transexuais
(2016), Pesquisa nacional sobre o ambiente educacional no Brasil 2015: as experiências de adolescentes e jovens lésbicas, gays, bissexuais, travestis e transexuais em nossos ambientes educacionais. Curitiba: ABGLT. Consultado a 20.06.18, em: http://static.congressoemfoco.uol.com.b r/2016/08/IAE-Brasil-Web-3-1.pdf.

Associação Nacional de Travestis e Transexuais (2018), Mapa dos assassinatos de travestis e transexuais no Brasil em 2017. Salvador: ANTRA. Consultado a $\quad 15.06 .18, \quad$ em https://antrabrasil.files.wordpress.com/2 018/02/relatc3b3rio-mapa-dosassassinatos-2017-antra.pdf.

Bento, Berenice (2017), O que é transexualidade. São Paulo: Editora Brasiliense. Consultado a 20.06.18, em: https://democraciadireitoegenero.files.w ordpress.com/2016/07/bento-bereniceo-que-c3a9-transexualidade2008.pdf.

Bobbio, Norberto (1996). A era dos direitos. Rio de Janeiro: Campus.

Brasil (1988), Constituição Federal de 1988. Promulgada em 5 de outubro de 1988. Consultado a 18.06.18, em: 
http://www.planalto.gov.br/ccivil_03/co

nstituicao/constituição.htm.

Brasil (2018); Projeto de Lei $\mathbf{n}^{\mathbf{0}}$ 134/2018. Dispõe sobre a criação do Estatuto da Diversidade Sexual. Brasília.

Brasil; Comitê Nacional de Educação em Direitos Humanos (2007), Plano Nacional de Educação em Direitos Humanos. Brasília: Secretaria Especial dos Direitos Humanos. Consultado a 18.06.18, em: http://portal.mec.gov.br/index.php?optio $\mathrm{n}=\mathrm{com} \_$docman\&view=download\&alia $\mathrm{s}=2191$-plano-nacionalpdf\&category_slug=dezembro-2009pdf\&Itemid=30192.

Brasil; Conselho Nacional de Combate à Discriminação; Ministério da Saúde (2004), Brasil sem homofobia. Brasília: Ministério da Saúde. Consultado a 18.06.18, em: http://bvsms.saude.gov.br/bvs/publicaco es/brasil_sem_homofobia.pdf.

Brasil; Ministério da Educação (2018). Resolução CNE/CP nº 01 , de 2018. Brasília.
Brasil; Ministério da Educação; Conselho Nacional de Educação (2012).

Parecer CNE/CP no 8/2012. Brasília. Consultado a 20.06.18, em: http://www.sdh.gov.br/assuntos/direitoparatodos/pdf/ParecerhomologadoDiretrizes NacionaisEDH.pdf.

Brasil; Secretaria de Direitos Humanos da Presidência da República (2013), Educação em Direitos Humanos: diretrizes nacionais. Brasília: Coordenação Geral de Educação da Secretaria Nacional de Promoção e Defesa dos Direitos Humanos. Consultado a 18.06.18, em: http://portal.mec.gov.br/index.php?optio $\mathrm{n}=\mathrm{com} \_$docman\&view=download \&alia $\mathrm{s}=32131$-educacao-dh-

diretrizesnacionais-

pdf\&category_slug=janeiro-2016-

pdf\&Itemid=30192.

Brasil; Supremo Tribunal Federal (2018), Ação Direta de Inconstitucionalidade $n^{0}$ 4275. Diário Oficial da União. Brasília.

Butler, Judith (2003), Problemas de gênero. Rio de Janeiro: Civilização Brasileira. 
Coordenação de Políticas Para a Diversidade Sexual (2017), Diversidade sexual e cidadania LGBT. $2^{\mathrm{a}}$ ed. São Paulo: IMESP.

Corte Interamericana de Direitos Humanos (2017), Opinião Consultiva OC $\mathbf{n}^{\mathbf{2}}$ 24/17. Consultado a 20.06.18, em:

http://www.corteidh.or.cr/docs/opinione s/seriea_24_esp.pdf.

Dias, Maria Berenice (2016), Homoafetividade e direitos LGBTI. $7^{\mathrm{a}}$ ed. São Paulo: Editora Revista dos Tribunais.

Dinis, Nilson Fernandes (2008), "Educação, relações de gênero e diversidade sexual", Educ. Soc., 29(103), 477-492. Consultado a 15.06.18, em http://www.scielo.br/pdf/es/v29n103/09 .pdf.

Gohn, Maria da Gloria (2009), "Educação não-formal, educador(a) social e projetos sociais de inclusão social”, Meta: Avaliação, 1(1), 28-43. Consultado a 20.07.18, em: http://revistas.cesgranrio.org.br/index.p hp/metaavaliacao/article/download/1/5.

Kant, Immanuel (1986), Fundamentação da Metafísica dos Costumes. Lisboa: Edições 70.

Luzzardi, Roberta do Espírito Santo; Cardoso, Adriana Lessa (2017), “A agroecologia sob a perspectiva do ecofeminismo: ato político para a autonomia de mulheres", in Amanda Basilio Santos et al. (orgs.). Interdisciplinaridade nas Ciências Humanas: Caminhos da pesquisa contemporânea. Jaguarão: CLAEC.

Organização das Nações Unidas - ONU (1948), Declaração Universal dos Direitos Humanos. Paris. Consultado a 20.07.18.

em: http://www.onu.org.br/img/2014/09/DU DH.pdf.

Organização dos Estados Americanos OEA (1969), Convenção Americana de Direitos Humanos (Pacto de San Jose da Costa Rica). San Jose. Consultado a 20.07.18, em: https://www.cidh.oas.org/basicos/portug ues/c.convencao_americana.htm. 
Organização Mundial da Saúde - OMS (2018), Classificação Estatística Internacional de Doenças e Problemas Relacionados com a Saúde (CID 11). $11^{\text {a }}$ rev. Consultado a 10.09 .18 , em: http://www.who.int/classifications/icd/e $\mathrm{n} /$.

Petry, Analídia Rodolpho; Meyer, Dagmar Elisabeth Estermann (2011), "Transexualidade e heteronormatividade: algumas questões para a pesquisa", Textos \& Contextos, 10(1), 193-198. Consultado a 19.06.18, em: http://revistaseletronicas.pucrs.br/ojs/in dex.php/fass/article/viewFile/7375/6434

Ribeiro, Getúlio. "Direitos humanos e diversidade: discrepâncias entre o fato e sua veiculação", in Mara Rejane Ribeiro; Getúlio Ribeiro (org.). Educação em direitos humanos e diversidade: diálogos interdisciplinares. Maceió: EDUFAL. Consultado a 15.07.18, em: http://www.ufal.edu.br/aedhesp/biblitec a-virtual/downloads/livro-educacaohumanos-e-diversidade-dialogosinterdisciplinares.

São Paulo (2001), Lei $\mathbf{n}^{0}$ 10.948, de 05 de novembro de 2001. Dispõe sobre as penalidades a serem aplicadas à prática de discriminação em razão de orientação sexual e dá outras providências. Consultado a 13.07.18, em: http://www.al.sp.gov.br/repositorio/legi slacao/lei/2001/lei-1094805.11.2001.html.

São Paulo (2014), Resolução SE $\mathbf{n}^{\circ}$ 45/2014. Dispõe sobre o tratamento nominal de discentes transexuais e travestis, no âmbito da Secretaria da Educação. Consultado a 13.07.18, em: http://siau.edunet.sp.gov.br/ItemLise/ar quivos/45_14.HTM?Time=30/10/2018 $\%$ 2021:12:03.

Scheibe, Elisa (2008), Direito de personalidade e transexualidade: a promoção da dignidade da pessoa humana em uma perspectiva plural. São Leopoldo, RS: Unisinos. Consultado a 15.06.18, em: http://www.repositorio.jesuita.org.br/bit stream/handle/UNISINOS/2430/ElisaSc heibeDireito.pdf?sequence=1\&isAllowe $\mathrm{d}=\mathrm{y}$.

Tosi, Giuseppe (2005), “Direitos humanos: reflexões iniciais", in Giuseppe Tosi (org.). Direitos humanos: história, teoria e prática. 


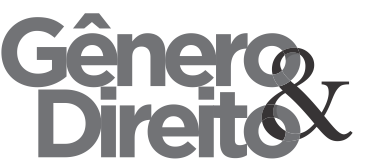

Periódico do Núcleo de Estudos e Pesquisas sobre Gênero e Direito

Centro de Ciências Jurídicas - Universidade Federal da Paraíba V. 8 - $\mathrm{N}^{\circ} 01$ - Ano 2019

ISSN | 2179-7137 | http://periodicos.ufpb.br/ojs2/index.php/ged/index

João Pessoa: $\quad$ Editora

$8 ?$ n_link=revista_artigos_leitura\&artigo

Universitária/UFPB. Consultado a

_id $=12914 \&$ revista_caderno $=14$

13.07.18,

em:

http://www.cchla.ufpb.br/ncdh/wp-

content/uploads/2015/11/2005.DH_.-

historia-teoria-pr\%C3\%A1tica.pdf.

Vianna, Cláudia Pereira (2015), “O

movimento LGBT e as políticas de educação de gênero e diversidade sexual: perdas, ganhos e desafios", Educ. Pesqui., 41(3), 791-806. Consultado a 18.06.18, em: http://www.scielo.br/pdf/ep/v41n3/1517 -9702-ep-1517-97022015031914.pdf.

Vieira, Tereza Rodrigues. "Aspectos psicológicos, médicos e jurídicos do transexualismo", Psicólogo Informação, 4(4), 74.

Viegas, Cláudia Mara de Almeida Rabelo, et al. (2013), "Os Direitos Humanos e de personalidade do transexual: prenome, gênero e a autodeterminação", Âmbito Jurídico, XVI(110). Consultado a 13.07.18, em: http://ambitojuridico.com.br/site/index.php/\%3Fn_li nk\%3Drevista_artigos_leitura\%26artigo _id\%3D13175\%26revista_caderno\%3D 